\title{
Editorial: Exploring organic agriculture's place within the agricultural revolution
}

The 10,000-year-old agricultural revolution continues. However, the nature of this revolution has changed in recent years-at least a little. During most of the last century, agricultural progress was described by systems that produced more crop and livestock products through the addition of 'external inputs'. Organic Agriculture has become an alternative to the industrialized systems that now dominate much of world agriculture. The organic movement started with scientists, farmers and gardeners who noticed the benefits to food production systems that emphasize integration, recycling and diversity. Organic Agriculture is the most popular current example of regenerative agriculture ${ }^{1}$ - where crop and livestock production are based on ecological principles ${ }^{2}$. By drawing on the resource-conserving aspects of traditional practices and the best modern ecological and agronomic knowledge, Organic Agriculture strives to meet the twin needs of sustainability and productivity. Today, Organic Agriculture is growing worldwide at both the production and consumer levels.

A great number of questions are being asked about Organic Agriculture. While ecologically based agricultural systems may sound good in principle, can they really advance agriculture-especially since they appear to reject the technologies that contributed so much to recent gains in food production? Is Organic Agriculture advancing the revolution, or is it just a counter-revolutionary distraction? These are important questions that deserve answers. Some answers to these questions are given in this special issue entitled 'Researching sustainable agricultural systems', based on selected short papers presented at the First Scientific Conference of the International Society of Organic Agriculture Research (ISOFAR) in September 2005 in Adelaide, SA, Australia.

Many agronomists question whether Organic Agriculture can provide high yields. 'How can farmers grow competitive crops without herbicides - especially in the face of so many weeds?' This is a legitimate question, especially given that we are still battling weeds in conventional agriculture after 50 years of herbicide use. Our ongoing 'war on weeds' has shaped the way industrial crop production is practised, and it has defined much of the way agronomists and farmers perceive weeds ${ }^{3}$. In this issue, Hauggaard-Nielsen et al. demonstrate that polyculturesintercrops of barley and legumes-enable crop plant communities to suppress weeds and suffer less disease, while at the same time maintaining productivity. This work clearly demonstrates that applying the basic ecological principles of diversity, competition and facilitation allows organic crops to be productive even in the face of pests. Also in this issue, Lukashyk et al. determined an optimum combination of plant competition and soil disturbance (tillage) for effective control of Canada thistle-one of Organic Agriculture's worst perennial weeds. This information will likely be music to the ears of researchers such as John Vandermeer, who has long since understood the ecological basis of alternative agriculture ${ }^{4}$, but whose views have not always been appreciated by agronomists. The challenge for agronomists will be to design site-specific polyculture systems and management schemes that work in different soil, climate and crop systems.

Questions also exist about organic livestock production-especially regarding animal health. In this issue, Haring et al. tested tanniferous legume plants for nematode control in sheep. They identified legume species that provided both high pasture yield and parasite control. Their research showed that a plant-based therapy may be an alternative solution for parasite control in livestockanother fascinating application of ecology in the food production system.

Climate change and energy supply concerns are rapidly changing how we think about agriculture. It is doubtful whether Organic Agriculture will be spared. While it is well-documented that organic farms require $40-50 \%$ less external energy than conventional farms ${ }^{5}$, little is known about how organic farms might become energy producers. In this issue, Halberg et al. identify the changes to land use and crop choice needed for a Danish cash crop farm to become more energy-independent through production of biodiesel from canola and biofuel from biomass. This study also raises new questions regarding the policy and infrastructure changes needed for such changes to occur in reality.

Environmental stewardship is just so important! For example, it is becoming clear that agriculture needs to be more answerable for greenhouse gas emissions. In this issue, Kustermann et al. present a detailed accounting of greenhouse gas emissions and energy use from organic and conventional farms. Their work was conducted using a modeling approach that considered $\mathrm{C}$ and $\mathrm{N}$ within soilplant-animal systems. The Kustermann et al. paper provides an excellent example of how to conduct greenhouse gas balance studies on a whole farm basis, and it stresses the need for interdisciplinary research teams. Readers will 
find the results of this particular paper encouraging, and they will learn that the superior greenhouse gas balance for the organic farm is very much a function of the farming system type (organic mixed grain-livestock farm compared with conventional grain farm). A similar reason was given by Hole et al. $^{6}$ for greater overall biodiversity on organic compared with conventional farms-more evidence that functional diversity at the farm level is an important contributor to environmental sustainability.

It is notable that all of the papers in the 'Researching Sustainable Agricultural Systems' special edition are European. Perhaps this reflects the reality that Organic Agriculture research is more advanced in the European Union than in other countries. Organic farming and organic farming research have been well supported financially in Europe for over 20 years. In fact, in this issue, Zander et al. reflect on the financial relevance of organic farming payments to European farmers. Results of their study will be of interest to policymakers elsewhere who are considering how to encourage a sustainable organic agricultural sector.

Three volunteered papers from the USA were added to this special issue to expand the focus beyond only the European experience. The first paper, by Tanaka et al., deals with practical research considerations for, and barriers to, integrated crop/livestock systems research in the Northern Plains. In the next paper, Conner et al. highlight the promise of pasture-raised livestock products for reconnecting producers and consumers in the USA. The final paper, by Bell and Raczkowski, presents the importance of proper measurement of selected soil properties in assessing short-term changes in soil quality as affected by tillage, organic and successional fallow management systems.

We conclude that Organic Agriculture will contribute positively to the agricultural revolution. Organic farming systems are forcing us to better understand the ecological basis of food production systems and they offer hope for a healthy environment.

\section{References}

1 Pearson, C.J. 2007. Regenerative, semiclosed systems: a priority for twenty-first-century agriculture. BioScience 57:409-418.

2 Gliessman, S.R. 2007. Agroecology: The Ecology of Sustainable Food Systems. 2nd ed. CRC Press, Boca Raton, FL.

3 Evans, C.L. 2002. The War on Weeds in the Prairie West: An Environmental History. The University of Calgary Press, Calgary, AB

4 Vandermeer, J. 1995. The ecological basis of alternative agriculture. Annual Review of Ecology and Systematics 26:201-224.

5 Hoeppner, J.W., Entz, M.H., McConkey, B., Zentner, B., and Nagy, C. 2005. Energy use and efficiency in two Canadian organic and conventional crop production systems. Renewable Agriculture and Food Systems 19:1-8.

6 Hole, D.G., Perkins, A.J., Wilson, J.D., Alexander, I.H., Grice, P.V., and Evans, A.D. 2005. Does organic farming benefit biodiversity? Biological Conservation 122:113-130.

Martin H. Entz Department of Plant Science, University of Manitoba, Winnipeg, MB, Canada R2T 2N2 m_entz@umanitoba.ca

Daniel Neuhoff Institute of Organic Agriculture, University of Bonn, Katzenburgweg 3, D-53115 Bonn, Germany d.neuhoff@uni-bonn.de

William Lockeretz Tufts University, Friedman School of Nutrition, 150 Harrison Ave. 02111, Boston, MA 02155, USA willie.lockeretz@tufts.edu 